\title{
Virtual Andragogy: A New Paradigm for Serving Adult Online Learners
}

\author{
Kimberly Greene, Lynn Larsen \\ Brandman University \\ United States of America
}

\begin{abstract}
Adult learners bring vast experience to learning opportunities and should have the maturity to stay motivated, focused, and engaged. Yet, in an online environment, many of the Andralogical ideals laid out by Malcolm Knowles can get lost. Focusing design and facilitation on what Brandman University's School of Education defines as Virtual Andragogy, requires a paradigm shift for what is considered best practices for creating online learning and teaching. We offer a new paradigm for such work through meaningful changes designers and instructors can bring to their practice that are empowering for adult learners in measurable and immeasurable ways. Lessons learned from the experiences of crafting and teaching online courses for adult students are analyzed to offer an examination of strategies that can empower instructors, instructional designers, and administrators. The goal is to allow for the presence of the instructor, fidelity of implementation, and emotional/cognitive support for the student.
\end{abstract}

\section{Introduction}

Adult online learning is one of the fastest growing segments of the educational world, yet, to date, the existing literature about how best to design and facilitate such learning for those outside of the traditional educational settings has been mostly smallscale and piecemeal [1]. One of the greatest challenges to a thorough exploration of the theories, tools, and practices that should be identified as ideal or most effective for serving the adult, online student is the lack a single framework that juxtaposes cogent knowledge of adult learners with the affordances of digital tools and virtual educational environments. Such a framework would enable designers and instructors to make informed decisions about how to best meet the needs of both the individual adult student and the learning objectives. With much of online, or distance, learning taking place via a learning management system (e.g., Blackboard, Canvas, or Moodle), a formal educational experience for the adult learner can take place with little interaction amongst students or between students and the instructor [2]. This issue has caused a great deal of concern for many Institutions of Higher Learning (IHL) as online learning courses "that are not designed to ensure [facultyinitiated, regular, and substantive] interaction between faculty and students should be classified as programs delivered via correspondence, not distance education" [3].

Rather than trying to modify pedagogical truisms, a new framework, Virtual Andragogy, is proposed to meet this need. Building upon the body of work of seminal educational, Virtual Andragogy offers an innovative, grounded theory for andragogicallyappropriate, constructivist-focused educational experiences that seek to serve adult students through authentic, transformational learning. The exploration of the key isolated constructs is as follows: Andragogy, Transformational Learning, Bloom's Revised Taxonomy, Constructivism, and Communities of Practice.

\section{Core Components}

Although many are not familiar with the term, andragogy has a history that spans over 180 years. It was first coined by Alexander Kapp, a German high school teacher, in his 1833 book on methods for teaching adults [4]. The term did not surface again until another German, Eugen Rosenstock-Huessy, discussed his views on the implementation of his ideas about andragogy starting in the early 1920s through the 1970s [4]. Eduard Lindeman, an important theorist in the field of andragogy, credited Rosenstock-Huessy with 
defining the term as separate from pedagogy and demagogy. "Andragogik [andragogy] represents the learning process as one in which theory and practice become one - a process according to which theoretical knowledge and practical affairs become resolved in creative experience" [5]. Lindeman published a book about andragogy, The Meaning of Adult Education in 1926, but the term "was not popularized until over four decades later" [6] when Malcolm Knowles published, The Modern Practice of Adult Education: Andragogy Versus Pedagogy in 1970. Malcolm Knowles, considered the father of andragogy, first wrote about the term in 1968 in the article, Andragogy, Not Pedagogy [4]. He viewed adult learners as "selfdirected and autonomous" [4] and that the role of the instructor was to facilitate the attainment and construction of knowledge.

The idea of andragogy being a core foundational element for transformational adult learning has been noted by multiple researchers [7] [8] [9]. Draper posits that, "being familiar with the evolution of andragogy is the foundation for professionalism in adult education" [6].

\subsection{Andragogy}

Although many are not familiar with the term, andragogy has a history that spans over 180 years. It was first coined by Alexander Kapp, a German high school teacher, in his 1833 book on methods for teaching adults [4]. The term did not surface again until another German, Eugen Rosenstock-Huessy, discussed his views on the implementation of his ideas about andragogy starting in the early 1920s through the 1970s [4]. Eduard Lindeman (1926), an important theorist in the field of andragogy, credited Rosenstock-Huessy with defining the term as separate from pedagogy and demagogy. "Andragogik [andragogy] represents the learning process as one in which theory and practice become one - a process according to which theoretical knowledge and practical affairs become resolved in creative experience" [5]. Lindeman published a book about andragogy, The Meaning of Adult Education in 1926, but the term "was not popularized until over four decades later" [6], when Malcolm Knowles published, The Modern Practice of Adult Education: Andragogy Versus Pedagogy in 1970. Malcolm Knowles, considered the father of andragogy, first wrote about the term in 1968 in the article, Andragogy, Not
Pedagogy [4]. He viewed adult learners as "selfdirected and autonomous" [4]. and that the role of the instructor was to facilitate the attainment and construction of knowledge.

\subsection{Transformational Learning}

Foote [10] describes how transformational learning can "frame adult experiences in new and exciting ways... [that] can involve a simple transformation of belief or opinion or a radical transformation involving one's total perspective" (p. 84). This echoes Merriam, Caffarella, and Baumgartner's [11] perspective that adult transformational learning can be a singular, revelatory experience, where a sudden recognition alters a previously accepted belief or truism. Reflection serves as the tipping point for the individual to recognize that an existing schemata or paradigm needs expansion or modification. Transformational learning alters not simply the "what" that is known in the mind of the individual, it also modifies the, "how we know" [12].

One hallmark of transformational learning is that cognitive engagement for the individual goes beyond the general accumulation of facts into the realm of understanding that supports integration across subjectspecific areas of study and application [13] [14] [15]. An additional hallmark is "perspective transformation" [14] where active, critical reflection by the learner is often brought about by a disorienting event or experience. This experience opens the individual's affective and/or cognitive understanding to a level of disequilibrium sufficient to inspire a desire or need for a different way of thinking, acting, feeling, or behaving.

Mezirow's thoughts on the power of transformational learning relate directly to the design and facilitation issues that lead to the development of Virtual Andragogy [15].

Transformative learning requires a form of education very different from that commonly associated with children. New information is only a resource in the adult learning process. To become meaningful, learning requires that new information be incorporated by the learner into an already well-developed symbolic frame of reference, an active process involving thought, feelings, and disposition. The learner may also have to be helped to transform his or her frame of reference to fully understand the experience. (p. 10) 


\subsection{Bloom's Revised Taxonomy}

In 1956, Benjamin Bloom, with several collaborators, put forth a taxonomy for categorizing educational objectives in order to share test items that assessed the same level of knowledge [16] [17]. Bloom believed the taxonomy could serve many educational functions beyond the correlation of examination questions, and the acceptance of the taxonomy by curriculum designers, educators, and researchers has validated his stance [18] [16] [17]. Bloom's focus for meaningful learning was predicated upon ensuring mastery as the ultimate desired outcome rather than memorization. The original taxonomy included six categories that were considered to be hierarchical. Each term represents a specific type of educational goal or objective that moved the learner's focus across a continuum from simple tasks to more complex ones, from concrete experiences to abstract comprehension (Armstrong, n.d; [16].

In 2001, a revision of Bloom's taxonomy was published as Bloom's Revised Taxonomy [19]. The revised taxonomy contains the categories of remember, understand, apply, analyze, evaluate, and create [16]. "Because the revision gives much greater weight to teacher usage, the requirement of a strict hierarchy has been relaxed to allow the categories to overlap one another" (p. 215) [17].

\subsection{Constructivism}

Smith, Hayes, \& Shea note that a "great deal of empirical research investigating the use of online and blended approaches in higher education and professional development has drawn primarily on social constructivist theories of learning" (p. 209) [20]. The core of such theories comes from the work of Vygotsky [21], specifically The Mind in Society (1978), where he identified learning as a "specific social nature and a process in which children grow into the intellectual life of those around them" (p. 88). His "zone of proximal development [ZPD]" (p. 90) concept, where the culturally-mediated interaction with teachers, peers, or other cognitive supports, affords a leap ahead in the individual's ability to do or know or understand. Vygotsky's ZPD construct often serves as the key foundational element in recent literature addressing the efficacy of online learning [20].
2.4.1. Affective. This domain focuses on emotions, feelings, attitudes, values, morals, ethics, and an individual's personal development [22]. While not specifically targeted in Bloom's original taxonomy, which focused solely on the cognitive domain [16], it was identified and recognized in Bloom's second book on the taxonomy [23].

2.4.2. Behavioral. Also known as the psychomotor domain, this paradigm for growth and understanding encompasses "productive skills" (p. 24) [22]. It also involves attempting to solve a problem or fix an issue in an active fashion where it is the choices and actions of the individual that bring about the change in the learner's understanding and knowledge.

2.4.3. Cognitive. Reigeluth divides his description of the cognitive domain into two categories: domaindependent and domain-independent [22]. The cognitive abilities that are domain-dependent are: knowing information and facts, targeted understandings and comprehension, and a specific set of skills considered appropriate for the subject, field, unit of study, or practice. The cognitive domain-independent abilities include: metacognitive focus on learning how to learn, thinking and problem-solving skills that extend beyond a singular focus, and learning strategies that can be transferred to other situations.

\subsection{Communities of Practice}

The initial concept of a Community of Practice first garnered attention with Lave and Wenger's, Situated Learning: Legitimate Peripheral Participation [24]. Wenger [25] alone published the seminal text on this concept, Communities of Practice: Learning, Meaning, and Identity. As an outgrowth of situated learning, the core understanding of Community of Practice $(\mathrm{CoP})$ is that the "social engagements provide the proper context for learning to take place" (p. 14) [24]. Communities of Practice are formed by people who engage in a process of collective learning in a shared human endeavor (e.g., a tribe learning to survive). That focus on the individual's engagement in the process of growth (affective, behavioral, and cognitive) needing to be legitimate is crucial for authentic learning in a $\mathrm{CoP}$ construct.

In regard to online learning, Riel and Polin [26] 
build distinct correlations to the essential value of designing for CoP educational environments with their identification of various types of such communities and a particular focus on Knowledge-Building Communities. They share the core elements of a CoP, and have the additional feature of deliberate and formal production of knowledge about its own practice. Where a traditional CoP shares its information as a general construct for the participating members, a knowledge building community is predicated upon people working together to craft new information as a collective group seeking greater expertise in their arena.

\section{Virtual Andragogy}

\subsection{General Design}

Virtual Andragogy synthesizes and aligns the key tenets of Bloom's (Revised) Taxonomy, Andragogy, Transformational Learning, Constructivism, and Communities of Practice into a single conceptual framework that guides the instructional design and facilitation of online learning for adult students. The framework supports both instructional designer and instructor, and by extension- the student- by providing a singular paradigm that illustrates the desired experience for the learner while providing individual engagement that is crucial for affective, behavioral, and cognitive growth and transformational learning.

\section{Core Tenets of Virtual Andragogy}

The essential tenet of Virtual Andragogy is the visual and cognitive illustration of the moving, active nature of learning along multiple continuums. Each adult student enters the course as a novice in that particular Community of Practice. It is only through mindfully engaging in authentic, scaffolded experiences that the individual can mature in knowledge, skill, and understanding to become an authentic, participating member of the CoP. As the learner is the focal point of the design, in contrast to the content, Mezirow's key elements that afford transformational learning are continuously engaged throughout the entirety of the learning process.

\subsection{The Model of Virtual Andragogy}

Virtual Andragogy illustrates the spiraling nature of the learner's progression, affectively, behaviorally, and cognitively, from novice to fully engaged, masterful practitioner. This growth in knowledge, skill, understanding, and application is fueled by the juxtaposition of the individual components of Bloom's Revised Taxonomy with the correlating precepts of andragogy. Rather than conceptualizing these complimentary constructs as separate spokes in a wheel, these linked concepts all work together, continuously moving in a non-hierarchical fashion. Every element must be engaged or the full potential of the learning experience will not be realized.

4.2.1. Readiness to learn and understanding. Readiness to learn is the why that spurs the motivation for the adult to return to formal learning. This correlates to the Bloom's conceptualization of understanding and its related verbs. Within a CoP, understanding is created when the individual engages in the process of crafting meaning through interactions with concepts, artifacts, other people in the community, as well as with one's own thoughts and reflections throughout such active and reflective experiences.

4.2.2. Need to know and remembering. Need to know is the self-aware element of the adult learner, the part of him or her that must feel the learning is useful and valuable. This aligns with Bloom's Revised Taxonomy's grouping of remembering verbs in that objectivist, factual knowledge, while considered a lower order thinking skill, is still relevant to one's engagement with the authentic language and tools or artifacts employed within a $\mathrm{CoP}$.

4.2.3. Experience and applying. In andragogy, the adult is one who has accumulated a reservoir of experience that becomes a resource for learning. This accumulation is to be positively acknowledged and harnessed to enhance the experience for the student. The Bloom's Revised Taxonomy verbs that connect with applying (e.g., changing, constructing, demonstrating, manipulating, relating, using) offer curriculum designers and instructors opportunities for adult learners to actively explore the behavioral component of the study through a comparative lens.

4.2.4. Orientation to learning and analyzing. The andragogical principal of orientation to learning highlights the adult learner's developmental ability to delay the need for an immediate sense of gratification, 
such as that which comes with focusing on quick memorization rather than acquiring deeper understanding. This requires an authentic level of maturity to willfully and mindfully enter into a state of cognitive dissonance for purposefully exploring, examining, and deconstructing to create understanding and meaning through experiences rather than having another simply tell you what should be memorized. This ability to purposefully modify one's orientation to learning from subject-centeredness to problem centeredness aligns with Bloom's Revised Taxonomy's category of analyzing and its related verbs (e.g., diagraming, deconstructing, differentiating, discriminating, and separating). The educational value in the actions described in this verb group demand the maturity of the problem-focused orientation to the learning to ensure the individual is affectively, behaviorally, and cognitively engaged in the process of creating meaning.

4.2.5 Self-concept and evaluating. Andragogy identifies how as an individual matures, one's selfconcept develops from dependency (i.e., needing approval and support for opinions and decisions) to self-directedness. A self-directed individual, especially one who is an authentic member of a $\mathrm{CoP}$, will still solicit advice or information from others, but ultimately is able to make one's own decisions and live with the consequences. The correlating Bloom's Revised Taxonomy verbs for evaluating (i.e., comparing, contrasting, defending, discriminating, interpreting, justifying) demand the ability of the learner to understand nuances of desired qualities within actions or outcomes enough to appropriately identify those levels in multiple forms.

4.2.6. Motivation to learn and creating. As an individual matures, his or her motivation to learn develops from an extrinsic to intrinsic focus; this correlates directly with the concept of movement within a CoP from peripheral participant to fully engaged member. The rewards for the effort it takes to make such progress must have authentic affective value for the individual or the behavioral and the cognitive focus will dissipate over time. This aligns directly with the Bloom's Revised Taxonomy verbs associated with creating (e.g., compiling, composing, devising, designing, generating, modifying, revising, summarizing) in that the focus and energy necessary to craft something new and meaningful cannot be maintained for a great length of time. Nor can it be transferred beyond the confines of any learning environment if the individual has not made the affective connections to find value in both the final artifact being created and the process necessary to make it.

\section{Summation and Final Reflections}

The outline of the core components of Virtual Andragogy, along with the illustration, offers a cognitive construct that seeks to empower instructors and designers to meaningfully integrate and employ the most critical aspects of the work of Knowles [4], Bloom [18], Mezirow [15], and Wenger [25]. The deconstruction and examination of each component of the proposed framework provides clarity on the complexity that is present in meaningful, effective application of the juxtaposed theories and concepts. Instructional designers and instructors can harness the affordances of these multiple constructs in a singular fashion to collaborate meaningfully in facilitating the affective, behavioral, and cognitive growth of today's twenty-first century adult learners seeking formal academic studies in the online modality.

\section{References}

[1] M. Simonson, C. Schlosser, and A. Orellana, "Distance education research: A review of the literature", Journal of Computing in Higher Education, Springer, NY, NY, 2011, pp. 124-142.

[2] D. McDonough, "Providing deep learning through active engagement of adult learners in blended courses", Journal of Learning in Higher Education, JW Press, online, 2014, pp. 916.

[3] Office of Inspector General, Semiannual report to Congress, No. 73, U.S. Department of Education, Washington D.C., 2016.

[4] J. Reischmann, “Andragogy. History, meaning, context, function", Andragogy.net, 2004.

[5] E. Lindeman, The meaning of adult education, New York: New Republic, 1926.

[6] J. Draper, "The metamorphoses of andragogy', Canadian Journal for the Study of Adult Education, 1998, pp. 3-26. 
[7] V. Arghode, E.W. Brieger, and G.N. McLean, "Adult learning theories: Implications for online Instruction", European Journal of Training and Development, 2017, pp. 593-609.

[8] G. Giannoukos, G., Besas, C. Galiropoulos, and V. Hioctour, "The andragogy, the social change and the transformative learning educational approaches in adult education", Journal of Education and Practice, 2015, pp. 4650 .

[9] H.M. Huang, "Toward constructivism for adult learners in online learning environments", British Journal of Educational Technology, 2002, pp. 27-37.

[10] L.S. Foote, "Transformational learning: Reflections of an adult learning story", Adult Learning, 2015, pp. 84-86.

[11] S.B. Merriam, R. Caffarella, and L.M. Baumgartner, Learning in adulthood: A comprehensive guide. Jossey-Bass, San Francisco: CA, 2007.

[12] R. Kegan, "What 'form' transforms? A constructivedevelopmental perspective on transformational learning", In J. Mezirow and Associates (Eds.), Learning as transformation: Critical perspectives on a theory in progress, pp. 35-69, Jossey-Bass, San Francisco, CA, 2000.

[13] L.M. Baumgartner, "An update on transformational learning", New Directions for Adult and Continuing Education, 2001, p. 89.

[14] C. Calleja, "Jack Mezirow's conceptualization of adult transformative learning: A review", Journal of Adult and Continuing Education, pp. 117-136.

[15] J. Mezirow, 'Transformative learning: Theory to practice", New Directions for Adult and Continuing Education, 1997, pp. 5-12.

[16] M. Forehand, "Bloom's taxonomy: Original and revised", In M. Orey (Ed.), Emerging perspectives on learning, teaching, and technology, 2005 (last updated October 11, 2017).

[17] D. Krathwohl, “A revision of Bloom's Taxonomy: An overview", Theory Into Practice,

2002, pp. 212-218.

[18] R. Brandt, "A conversation with Benjamin Bloom", Educational Leadership, 1979, pp. 157-61.

[19] L. Anderson, and D. Krathwohl (Eds.). A taxonomy for learning, teaching, and assessing: A revision of Bloom's taxonomy of educational objectives. NY, NY: Longman, 2001.

[20] S.U. Smith, S. Hayes, and P. Shea, "A critical review of the use of Wenger's Community of Practice $(\mathrm{CoP})$ theoretical framework in online and blended learning research, 20002014”, Online Learning, 2017, pp. 209-237.

[21] L.S. Vygotsky, Mind in Society. Harvard University Press, Cambridge, MA, 1978.

[22] C.M. Reigeluth, Instructional-design Theories and Models: A New Paradigm of Instructional Theory, Volume II (Instructional Design Theories and Models), Lawrence Erlbaum Associates, Mahwah, NJ, 1999.

[23] K. Davis, Y. Chen, and M. Campbell, "Bloom Biography”, 2010, Retrieved December 2, 2017, online.

[24]. J. Lave, and E. Wenger, Situated learning: Legitimate peripheral participation. Cambridge University Press. Cambridge: UK, 1991.

[25] E. Wenger, Communities of practice: Learning, meaning, and identity. Cambridge University Press, Cambridge, UK, 1998.

[26] M. Riel, and L. Polin, "Designing for virtual communities in the service of learning" In R.

Barab Kling and J.H. Gray (Eds.), Online learning communities: Common ground and critical differences in designing technical environments, Cambridge University Press, Cambridge; UK, 2004, pp. 6-50). 